\title{
Impact of Capital Market Integration on Skilled-Unskilled Labor Choice
}

\author{
Hikaru Ogawa \\ University of Tokyo, Tokyo, Japan \\ Masafumi Tsubuku \\ Nagoya University, Nagoya, Japan
}

\begin{abstract}
This study examines how capital market integration, induced by globalization, affects skilled-unskilled labor choices. Our results show that market integration fosters competition for mobile capital among countries, inducing governments to employ domestic policies that are favorable for skilled workers. These policy changes induce individuals to become skilled workers, thereby raising the skilled-unskilled labor ratio. We examine the efficiency of the aforementioned ratio in integrated markets and show that the supply of skilled (unskilled) labor in equilibrium is excessive (deficient) because education in one country might create negative externalities in others.
\end{abstract}

JEL Classifications: H21, H77

Keywords: Capital Tax Competition, Skilled Labor, Unskilled Labor, Market Integration

\footnotetext{
* Corresponding Author: Masafumi Tsubuku; Graduate School of Economics, Nagoya University, Furocho Chikusaku, Nagoya 4648601, Japan, Tel: +81527894926, Fax: +81527894924, Email: msfm.tbk@gmail.com

Co-Author: Hikaru Ogawa; Graduate School of Economics and Graduate School of Public Policy, University of Tokyo, 7-3-1 Hongo Bunkyoku, Tokyo 113-0033, Japan, Tel: +81358415574, Fax: +81358415521, Email: ogawa@e.u-tokyo.ac.jp.
}

Acknowledgements: This research is funded by Japan Society for Promoting Science (no. 25245042 and 15J11103). This is a revised version of a paper presented at the UC Irvine-Waseda Workshop on Public Policy. The authors acknowledge anonymous referees for the comments. 


\section{Introduction}

Increased factor mobility exerts multiple influences on government policies, and numerous theories about tax competition propose how governments react to market integration. The literature on tax competition customarily argues that increased factor mobility drives down the tax rates imposed on such factors to inefficiently low levels, thereby warranting international coordination of tax polices (Zodrow and Miezskowski 1986, Wilson 1986).

Another common view in this literature is that factor mobility prompts the redistribution of domestic income to inefficiently low levels (Gerber and Hewitt 1987, Wildasin 1991, 1995, Hindriks 1999, Kessler et al. 2002, Cremer and Pestieau 2004, Lee 2007, Hong and Smart 2010). The logic behind this argument is that income redistribution creates locational incentives that attract those who benefit from redistribution and repel rich contributors. Thus, governments hesitate to increase the magnitude of income redistribution.

Although preceding studies have examined how general factor mobility influences government policy, we clarify how factor mobility, particularly capital mobility, influences skilled-unskilled labor choices. The types of individuals are given in the previous studies, but all self-interested individuals react to shifts in government policies. Therefore, it is essential to analyze the overall impact of capital mobility by examining how individuals react when governments shift policy following capital market integration; otherwise, the primary effects on equilibrium via individuals' reactions may remain obscured or some problems may be left unanswered.

Increasing globalization enhances factor mobility and apparently induces individuals to seek higher education. Figure 1 compares the globalization index and college-going rate across 148 countries in 2012 and shows that two indicators exhibit a strong positive relation: the higher the globalization index, the higher the college-going rate. In the present study, we first present a theoretical model that explains the positive relation between globalization and investment in education through the analysis of capital market integration. Second, we study the efficiency of the skilled-unskilled labor choices made by individuals in the integrated market. Treating labor status as the outcome of the choices made by individuals, we examine the efficiency of investment in education through the skilled-unskilled labor ratio. 


\section{Figure 1. Globalization index and college-going rate}

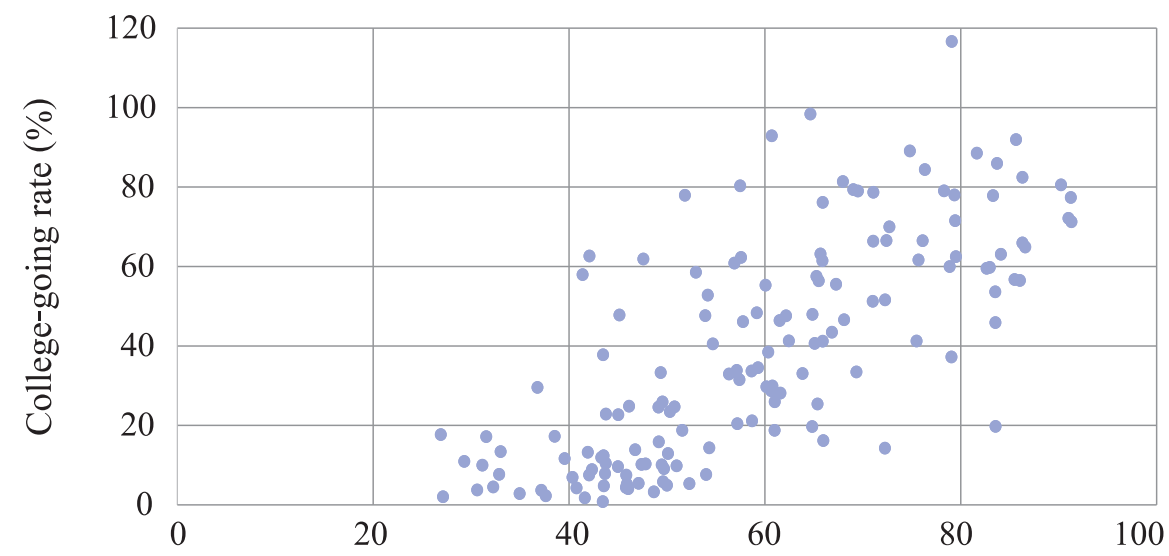

Globalization index

(Source) The college-going rate is from the United Nations Educational Scientific and Cultural Organization Institute for Statistics. It measures the advancement rate for junior (two-year) and senior (four-year) colleges, which corresponds to level 5 8 of International Standard Classification of Education 2012. The globalization index is based on the 2012 KOF Index of Economic Globalization.

The two studies approximating ours are Gerber and Hewitt (1987) and Kessler et al. (2002). The former analyzes the efficiency of domestic income redistribution policies when capital is mobile but skilled and unskilled workers are not. ${ }^{1}$ The latter examines how factor mobility affects redistribution policy by assuming initial capital endowments are unevenly distributed among individuals. Their models are different, but these have confirmed that local redistribution policies are inefficient from a social welfare perspective, which is analogous to our findings.

However, Gerber and Hewitt (1987) and Kessler et al. (2002) address only shortterm equilibrium where individuals have no chance of becoming either skilled/rich or unskilled/poor labor through educational training. In particular, policy shifts that alter the redistribution of income from skilled to unskilled workers create incentives to remain

\footnotetext{
'The relation between capital market integration and human capital formation has been addressed in preceding studies. Gradstein and Justman (1995) show that two countries competing for mobile capital choose excessive education subsidies. Viaene and Zilcha (2002a) develop an economic growth model to show that public education spending rises when capital markets integrate. Viaene and Zilcha (2002b) study the impacts of capital market integration on the income distribution using a similar framework. Egger et al. (2010) present a dynamic model and show that capital inflows (outflows) raise (reduce) attainment of higher education.
} 
unskilled only in the long and medium terms after capital markets integrate. In contrast, we focus on how changes in income redistribution following capital market integration affect personal educational choices. Results from our model reveal that workers' skilledunskilled labor choices under factor mobility explain the relation shown in Figure 1. The endogenous choice of labor status also allows us to examine the efficiency of the skilledunskilled labor ratio in equilibrium.

We initially find that increased capital mobility incentivizes workers to upgrade skills through education, resulting in a higher ratio of skilled to unskilled labor. Changes in the incentive to acquire skills arise when governments compete for mobile capital after markets integrate. Because skilled labor better complements capital, capital-seeking governments encourage workers to become skilled. National marginal productivity of capital increases with more skilled labor and attracts capital. Governments formulate policies favoring skilled workers and, in doing so, reduce the magnitude of redistribution policy.

Second, this study's results reveal that the supply of skilled (unskilled) labor in equilibrium becomes excessive (deficient). This happens because income redistribution generates positive fiscal externalities even if skilled and unskilled workers are immobile; therefore, the magnitude of domestic income redistribution is inefficient. Inefficient income redistribution incentivizes workers to become over-skilled, wasting a portion of society's investment in education.

Two policy implications arise from our results. It is a standard argument that the progress of capital mobility associated with market integration improves the efficiency of capital allocation among countries. In addition to this, based on our first result, the capital market integration should be further advocated since it increases the individuals' incentives to be educated, and thus it enhances human capital accumulation. The effect of market integration on the incentive for education is worthy to mention in the long-term perspective since the accumulation of human capital caused by the market integration enhances the economic growth. In this sense, our results provide the policy implication that the impact of market integration is not confined in the choice of education level, but it rather appears in the long-run growth. From the second result, we find that international coordination is needed not only for the development of market integration, but also for the policies that support low-income earners. Due to the integration of capital market, the government tends to reduce the size of domestic redistribution excessively. This requests the international policy coordination to avoid the excess reduction of redistribution. However, international coordination on the size of redistribution is difficult to implement 
and is typically not observed in practice. In this case, alternate solution is needed, and one of them would be the harmonization of education schemes among countries to avoid the excess investment for education.

This paper proceeds as follows. Section II introduces a baseline model in which workers choose between pursuing or not pursuing education to enhance job skills. It identifies the properties of equilibrium that drive the results in Section III under symmetric equilibrium. Section IV extends the analysis to an asymmetric two-country model and extends the model to discuss the formulation of government policy and objectives. Section V concludes.

\section{Model}

\section{A. Technology and preferences}

Consider two symmetric countries. Total population in each country $i(i=1,2)$ is normalized to 1 . Production of private goods in country $i$ requires capital and two types of labor. We assume production in country $i$ observes the function $Y_{i}=F\left(K_{i}, S_{i}\right)+b L_{i}$, where $K_{i}$ is the quantity of capital in country $i, S_{i}$ is the quantity of skilled labor, and $L_{i}$ is the quantity of unskilled labor. ${ }^{2} b(>0)$ denotes the productivity of unskilled labor, assumed to be given. We assume $F\left(K_{i}, S_{i}\right)$ is concave and homogeneous of degree one, rendering the national production function constant returns to scale with respect to $K_{i}, S_{i}$, and $L_{i}$. We assume capital and labor are complements in production $\left(F_{K S}>0\right)$.

The resident's preference in country $i$ is given by $u\left(c_{i j}, g_{i}\right)=c_{j i}+u\left(g_{i}\right)$, where $c_{j i}$ is consumption of a private numeraire good of type $j$ labor, where $j=S$ is denoting the consumption of skilled labor and $j=L$ denoting that of unskilled labor. $g_{i}$ denotes a public good financed by a unit tax on mobile capital. The government of country $i$ provides a public good financed solely by taxing capital. To avoid tax competition among countries, the tax rate in each country $i,\left(T_{i}\right)$, is assumed to be harmonized, identical, and fixed: $T_{1}=T_{2}=\bar{T}>0$. The budget constraint of country $i$ becomes

${ }^{2}$ Galor and Weil (1996) introduced this type of production function, which is widely used to analyze skilled and unskilled labor. 


$$
g_{i}=\bar{T} K_{i}
$$

\section{B. Firms}

The firm's profit in country $i$ is $\Pi_{i}=Y_{i}-w_{S i} S_{i}-w_{L i} L_{i}-\left(r_{i}+\bar{T}\right) K_{i}$, where $w_{S i}$ is the wage of skilled labor, $r_{i}$ is the price of capital, and $w_{L i}$ is the wage of unskilled labor in country $i$. Solving the firm's optimization problem in country $i$, we have

$$
\begin{gathered}
F_{K i}\left(K_{i}, S_{i}\right)=r_{i}+\bar{T}, \\
b=w_{L i} .
\end{gathered}
$$

Equation (2) and Equation (3) show that the quantity of capital in the country affects wage of skilled labor only; wage of unskilled labor remain constant at $b$.

\section{Residents}

Residents in country $i$ are endowed with identical quantities of capital and receive rent $r \bar{K}_{l}$ from investment. They also earn labor income; as all residents supply one unit of labor, each skilled (unskilled) worker receives $w_{S i}\left(w_{L i}\right)$. Residents choose between supplying skilled or unskilled labor. Skilled workers spend $\tau_{i} \in[0,1]$ for education. We assume educational costs differ with individuals and that types of individuals in country $i$, $\left(\tau_{i}\right)$ are uniformly distributed along a unit interval.

The utility functions of skilled and unskilled workers are

$$
\begin{gathered}
U_{S i}=w_{S i}{ }^{-} \tau_{i}-\left(\bar{\theta}+\theta_{i}\right)+r_{i} \bar{K}_{l}+u\left(g_{i}\right) \text { and } \\
U_{L i}=w_{L i}+\frac{R_{i}}{L_{i}}+r_{i} \bar{K}_{l}+u\left(g_{i}\right),
\end{gathered}
$$

where $\bar{\theta}+\theta_{i}$ denotes a lump-sum tax imposed on skilled labor to redistribute income from skilled to unskilled workers and $R_{i}$ represents the amount of income redistributed: $R_{i} \equiv\left(\bar{\theta}+\theta_{i}\right) S_{i}$. Here, $\bar{\theta}$ is a lump-sum tax to finance income transfers within a standard of fairness. $\theta_{i}$ denotes the extent to which government $i$ enlarges or reduces income 
redistribution. The government curtails redistributed income below levels required by the fairness concern if $\theta_{i}<0$. It strengthens the income redistribution policy if $\theta_{i}>0$. To simplify the notation, however, we assume $\bar{\theta}=0$ without loss of generality.

Utility maximization means selecting the maximum of $U_{S i}$ and $U_{L i}$. Residents who incur education $\operatorname{cost} \tau_{i}^{*}$ derive identical utilities from being skilled or unskilled, where

$$
\tau_{i}^{*}=w_{S i}-w_{L i}-\theta_{i}-\frac{R_{i}}{L_{i}}
$$

The supply of skilled and unskilled labor is thus given by

$$
\begin{aligned}
& S_{i}=\tau_{i}^{*} \text { and } \\
& L_{i}=1-\tau_{i}^{*} .
\end{aligned}
$$

\section{Markets}

A resident of country $i$ has initial capital endowment $\bar{K}$, making $2 \bar{K}$ the quantity of national capital employed for production. If capital markets are not integrated, capital is fixed in place and its net return (marginal product of capital investment) is not equalized between two countries $\left(r_{i} \neq r_{j}\right)$. Perfectly mobile capital relocates to seek higher returns, which is one of the greatest benefits of capital market integration. To maximize total output in the whole economy, it is desirable to allocate more capital to the country offering a higher return on investment. An intuitive reason is clear. Imagine the marginal product of capital (return on investment) in Country 1 is higher. Shifting one unit of capital from Country 2 to Country 1 reduces output slightly in Country 2 but significantly raises output in Country 1 , such that the latter positive effect exceeds the former negative effect. If the marginal product in Country 2 exceeds that in Country 1, reallocating capital to Country 2 raises total global output. Thus, capital mobility allocates resources (capital) more efficiently as $r_{1}-r_{2}$ converges to 0 .

Market-clearing conditions in the capital market are given by

$$
r=F_{K i}\left(K_{i}, S_{i}\right)-\bar{T} \text { and }
$$




$$
2 \bar{K}=K_{1}+K_{2}
$$

In practice, capital market integration originates either indirectly through mobility of financial assets or directly through mobility of investment of retained earnings (Allen and Stein 1990). In either cases, the investment relocates to countries offering the highest rate of return, and net return on investment equalizes as shown in Equation (9).

Total population, normalized to 1 , is composed of skilled and unskilled labor:

$$
S_{i}+L_{i}=1
$$

\section{E. Policy effects}

Demand for skilled and unskilled labor is described by Equation (2) and Equation (3), and using second-order conditions $\left(F_{S K}\right)^{2}-F_{S S} F_{K K}<0$ and $F_{K S}>0$, we have the following comparative statics:

$$
\begin{gathered}
\frac{d S_{i}}{d \theta_{i}}=-\frac{\left(F_{S K}\right)^{2}-2 F_{K K} A_{2}}{|D|\left(1-S_{i}\right)}<0, \\
\frac{d L_{i}}{d \theta_{i}}=-\frac{d S_{i}}{d \theta_{i}}>0, \\
\frac{d\left(S_{i} / L_{i}\right)}{d \theta_{i}}=\frac{1}{L_{i}^{2}}\left(L_{i} \frac{d S_{i}}{d \theta_{i}}-S_{i} \frac{d L_{i}}{d \theta_{i}}\right)=\frac{1}{L_{i}^{2}} \frac{d S_{i}}{d \theta_{i}}<0, \\
\frac{d r}{d \theta_{i}}=-\frac{\left[\left(F_{S K}\right)^{2}-2 F_{K K} A_{j}\right] F_{S K}}{|D|\left(1-S_{i}\right)}<0, \\
\frac{d K_{i}}{d \theta_{i}}=-\frac{F_{S K} A_{j}}{|D|\left(1-S_{i}\right)}<0, \text { and } \\
\frac{d S_{j}}{d \theta_{i}}=-\frac{\left(F_{S K}\right)^{2}}{|D|\left(1-S_{i}\right)}>0,
\end{gathered}
$$


where

$$
\begin{gathered}
A_{i} \equiv\left[F_{S S}-\left(1+\frac{\theta_{i}}{\left(1-S_{i}\right)^{2}}\right)\right]<0 \text { and } \\
|\mathrm{D}| \equiv-F_{S K}\left(A_{1}+A_{2}\right)+2 F_{K K} A_{1} A_{2}<0 .
\end{gathered}
$$

Equation (12) and Equation (13) show that redistributing more domestic income limits workers' incentives to seek additional education and heightens their incentive to remain less skilled. Equation (12) and Equation (13) imply that the skilled-unskilled labor ratio increases as more income is redistributed, as shown in Equation (14).

Equation (16) reveals that redistributing more income in country $i$ induces capital outflows because country $i$ loses investment appeal when supply of skilled workers declines. Capital fleeing country $i$ enters country $j$, which increases marginal productivity of skilled labor in country $j$. Therefore, the supply of skilled workers in country $j$ increases as shown in Equation (17).

\section{Effects of Market Integration}

\section{A. Modeling capital market integration}

Factors that discourage capital mobility generate inter-regional price differentials. Those differentials signal regional disparities in marginal productivity of capital and potential for inefficient capital allocation. Integration facilitates mobility of capital and regional convergence in its price. The European Union, the Organisation for Economic Co-operation and Development, and numerous Asian countries have made concerted efforts to enhance mobility of capital by integrating markets. Their efforts include abolishing exchange restrictions, establishing concurrent accounting standards, and consolidating settlement and clearing systems. These measures are intended to encourage free flow of capital, particularly personal capital, direct investment, sale and purchase of listed securities, and issuing bonds on foreign markets.

In the following analysis, we first model autarky wherein capital markets are not 
integrated, i.e., capital is immobile. The allocation of capital is such that $\bar{K}_{l}=K_{i}$. Next, we characterize capital market integration as the lifting of curbs that restrict capital mobility and promote equalization of net returns on investment across countries.

A representative argument for integration is that it induces capital flows that equate the marginal productivity of capital investment as mentioned above. We carry forward with this efficiency-enhancing aspect of capital market integration but delve further into the effects of market integration on personal education. The potential cost of capital market integration as related to our analysis is distortions arising from a race to the bottom: countries lower tax rates to lure investment and, in doing so, set rates inefficiently low. ${ }^{3}$ This drawback to integration appears in our model: governments curtail domestic redistribution of income to lure capital by encouraging workers to improve skills.

\section{B. Redistribution policy}

An example of redistribution policy is the imposition of a lump-sum tax on skilled labor. The collected revenue is then distributed to unskilled workers in a lump sum $\left(R_{i}=\right.$ $\left.\theta_{i} S_{i}\right)$. We assume the government in each country is benevolent and maximizes residents' total utility. The objective function for the government in country $i$ is given by

$$
\begin{aligned}
W_{i} & \equiv \int_{0}^{\tau_{i}^{*}} U_{s i} d \tau_{i}+\int_{\tau_{i}^{*}}^{1} U_{L i} d \tau_{i} \\
& =\int_{0}^{\tau_{i}^{*}}\left(w_{s i}-\tau_{i}-\theta_{i}+r \bar{K}_{l}+u\left(g_{i}\right)\right) d \tau_{i}+\int_{\tau_{i}^{*}}^{1}\left(w_{L i}+\frac{S_{i}}{L_{i}} \theta_{i}+r \bar{K}_{l}+u\left(g_{i}\right)\right) d \tau_{i} \\
& =\left(w_{s i}-\theta_{i}\right) \tau_{i}^{*}-\int_{0}^{\tau_{i}^{*}} \tau_{i} d \tau_{i}+\left(1-\tau_{i}^{*}\right) w_{L i}+\tau_{i}^{*} \theta_{i}+r \bar{K}_{l}+u\left(g_{i}\right) \\
& =\tau_{i}^{*} w_{S i}-\int_{0}^{\tau_{i}^{*}} \tau_{i} d \tau_{i}+\left(1-\tau_{i}^{*}\right) w_{L i}+r \bar{K}_{l}+u\left(g_{i}\right) .
\end{aligned}
$$

Since we assume a production function with constant returns to scale from our three inputs, we have

\footnotetext{
${ }^{3}$ Here, we introduce two subjects discussed in economic literature, but diverse opinion exists about merits and drawbacks of capital market integration. Agenor (2003) categorizes the benefits as international risk-sharing, enhanced discipline that reduces the frequency of policy mistakes, and increased efficiency. Drawing from the recent two decades of economic experience, he cites its potential costs as uneven distribution of capital among countries, inadequate domestic allocation of capital inflows and outflows, macroeconomic instability, pro-cyclicality in short-term capital flows, and volatility of capital flows.
} 


$$
F\left(S_{i}, K_{i}, L_{i}\right)=F_{S i} S_{i}+F_{K i} K_{i}+b L_{i}=w_{S i} \tau_{i}^{*}+(r+\bar{T}) K_{i}+w_{S i}\left(1-\tau_{i}^{*}\right) .
$$

We rewrite the objective function using Equation (19) as

$$
W_{i}=F\left(S_{i}, K_{i}, L_{i}\right)-\bar{T} K_{i}+r\left(\bar{K}_{l}-K_{i}\right)-\frac{\left(\tau_{i}^{*}\right)^{2}}{2}+u\left(g_{i}\right) .
$$

When capital markets are not integrated and capital is fixed in-country $\left(\bar{K}_{l}=K_{i}\right)$, the first-order condition of government's maximization problem is given by

$$
\frac{\partial W_{i}}{\partial \theta_{i}}=F_{S i} \frac{\partial S_{i}}{\partial \theta_{i}}+b \frac{\partial L_{i}}{\partial \theta_{i}}-\tau_{i}^{*} \frac{\partial \tau_{i}^{*}}{\partial \theta_{i}}=\frac{\theta_{i}}{L_{i}} \frac{\partial S_{i}}{\partial \theta_{i}}=0
$$

Since $\partial S_{i} / \partial \theta_{i} \neq 0$, the optimal redistribution satisfies

$$
\theta_{i}=0
$$

Since we assume that individuals' preferences are characterized by a quasi-linear utility function and that the government simply maximizes the sum of individuals' utilities, has no incentive to redistribute income internally. This circumstance allows investigation into the shifts in domestic income redistribution when capital markets integrate.

\section{Market integration}

Under integrated capital markets, the maximization of $W_{i}$ with respect to $\theta_{i}$ gives

$$
\frac{\partial W_{i}}{\partial \theta_{i}}=F_{S i} \frac{\partial S_{i}}{\partial \theta_{i}}+F_{K i} \frac{\partial K_{i}}{\partial \theta_{i}}+b \frac{\partial L_{i}}{\partial \theta_{i}}-(\bar{T}+r) \frac{\partial K_{i}}{\partial \theta_{i}}+\left(\bar{K}_{l}-K_{i}\right) \frac{\partial r}{\partial \theta_{i}}-\tau_{i}^{*} \frac{\partial \tau_{i}^{*}}{\partial \theta_{i}}+u_{g i} \frac{\partial g_{i}}{\partial \theta_{i}} .
$$

From Equation (7) and Equation (8), we have at the equilibrium

$$
\frac{\partial \tau_{i}^{*}}{\partial \theta_{i}}=\frac{\partial S_{i}}{\partial \theta_{i}}=-\frac{\partial L_{i}}{\partial \theta_{i}}
$$


Using $\tau_{i}^{*}=w_{S i}-w_{L i}-\theta_{i} S_{i} / L_{i}$, we rewrite Equation (22) as

$$
\begin{gathered}
\frac{\partial W_{i}}{\partial \theta_{i}}=\left(F_{S i}-w_{S i}-\theta_{i}\right) \frac{\partial S_{i}}{\partial \theta_{i}}+\left(b-w_{L i}\right) \frac{\partial L_{i}}{\partial \theta_{i}}+\left(\bar{K}_{l}-K_{i}\right) \frac{\partial r}{\partial \theta_{i}}-\left(-1-\frac{S_{i}}{1-S_{i}}\right) \theta_{i} \frac{\partial S_{i}}{\partial \theta_{i}} \\
+u_{g i} \frac{\partial g_{i}}{\partial \theta_{i}}=\left(\bar{K}_{l}-K_{i}\right) \frac{\partial r}{\partial \theta_{i}}+\frac{\theta_{i}}{1-S_{i}} \frac{\partial S_{i}}{\partial \theta_{i}}+u_{g i} \frac{\partial g_{i}}{\partial \theta_{i}}=0 .
\end{gathered}
$$

By solving $\theta_{i}$, we obtain redistribution policy in the equilibrium:

$$
\theta_{i}^{*}=L_{i} \frac{\left(\bar{K}_{l}-K_{i}\right)\left(\partial r / \partial \theta_{i}\right)+u_{g i} \bar{T}\left(\partial K_{i} / \partial \theta_{i}\right)}{-\left(\partial S_{i} / \partial \theta_{i}\right)} .
$$

Equation (24) reduces to Equation (21) when capital markets are not integrated: $\bar{K}_{l}=K_{i}$ and $\partial K_{i} / \partial \theta_{i}=0$. In the symmetric equilibrium, $\bar{K}_{l}=K_{i}$ holds. ${ }^{4}$ Hence, we have

$$
\theta_{i}^{*}=L_{i} \frac{u_{g i} \bar{T}\left(\partial K_{i} / \partial \theta_{i}\right)}{-\left(\partial S_{i} / \partial \theta_{i}\right)}<0
$$

The last inequality comes from Equation (12) and Equation (16). Comparing redistribution policy before and after market integration-i.e., Equation (21) and Equation (25), respectively-yields Lemma 1, which replicates findings presented by Gerber and Hewitt (1987).

Lemma 1: After capital markets integrate, the government curtails income redistribution $\left(\theta_{i}\right)$.

The government curtails redistribution following market integration because instituting policies favoring skilled labor encourages workers to acquire skills. Doing so increases marginal productivity of capital as skilled labor and capital are complements in production $\left(F_{K S}>0\right)$. As capital flows into a country, tax revenues rise, as does the provision of public goods. Juxtaposing Equation (12) and Equation (13) with Lemma 1 yields Proposition 1.

\footnotetext{
${ }^{4}$ In asymmetric equilibrium, results in this subsection still hold for country $i$, which exports capital $\left(\bar{K}_{l}>K_{i}\right)$. The term $\left(\bar{K}_{l}-K_{i}\right)\left(d r / d \theta_{i}\right)$, which represents the terms-of-trade effect, is simply added.
} 
Proposition 1: After capital markets integrate, workers have incentive to acquire skills.

\section{Efficiency}

The fact that governments curtail income redistribution after capital markets integrate implies that redistributions policies involve a race to the bottom in redistribution policies. Indeed, this race to the bottom even occurs when neither skilled nor unskilled labor is mobile. Moreover, a policy of curtailing redistribution implies that the symmetric equilibrium policy is inefficiently low, as confirmed by deriving the externalities of a curtailing redistributions:

$$
\begin{aligned}
\frac{\partial W_{j}}{\partial \theta_{i}} & =F_{S j} \frac{\partial S_{j}}{\partial \theta_{i}}+F_{K j} \frac{\partial K_{j}}{\partial \theta_{i}}+b_{j} \frac{\partial L_{j}}{\partial \theta_{i}}-\bar{T} \frac{\partial K_{j}}{\partial \theta_{i}}-r \frac{\partial K_{j}}{\partial \theta_{i}}+\left(\bar{K}_{j}-K_{j}\right) \frac{\partial r}{\partial \theta_{i}} \\
& -\tau_{j}^{*} \frac{\partial \tau_{j}^{*}}{\partial \theta_{i}}+u_{g} \frac{\partial g_{j}}{\partial \theta_{j}}=\left(\bar{K}_{j}-K_{j}\right) \underbrace{\frac{\partial r}{\partial \theta_{i}}}_{-}+\frac{\theta_{j}}{1-S_{j}} \underbrace{\frac{\partial S_{j}}{\partial \theta_{i}}}_{+}+u_{g} \underbrace{\frac{\partial g_{j}}{\partial \theta_{j}}}_{+} .
\end{aligned}
$$

Using $K_{i}=\bar{K}_{l}$ in the symmetric equilibrium, we find that $d W_{j} / d \theta_{i}>0$. Lemma 2 arises.

Lemma 2: Governments pursue inefficiently low redistribution policies when capital markets integrate.

A reduction in $\theta_{i}$ diminishes welfare of other countries via two channels. First, a reduction in $\theta_{i}$ increases the supply of skilled labor and therefore capital in country $i$. The increase in capital directly reduces the quantity of capital in country $j$, which erodes its tax base. The reduced tax base reduces provision of public goods and thereby reduces the welfare in country $j$.

The second channel is income redistribution policy. The reduction in $\theta_{i}$ reduces the quantity of capital in country $j$ as in the first channel. This reduction in capital decreases the supply of skilled workers in country $j$ and implies less income is transferred to unskilled workers, whereby their welfare is diminished. Overall, neither channel is considered by the government's choice of $\theta_{i}$, suggesting the emergence of negative externalities when its value falls. Income redistribution becomes too low compared with the efficient level, suggesting Proposition 2. 
Proposition 2: When capital markets integrate, the supply of skilled (unskilled) labor becomes excessive (deficient).

The policy of curtailing income redistribution induces workers to acquire skills. The fact that skilled (unskilled) labor in the equilibrium is excessive (deficient) indicates workers spend too much to acquire skills.

\section{Discussion}

\section{A. Asymmetric countries}

Analysis in Section III assumed our two countries are symmetric, as justified to avoid complicated computation. However, studies particularly note how asymmetries between two countries affect equilibrium outcomes (Bucovetsky 1991, Wilson 1991, Peralta and van Ypersele 2005). In our two-country model, the asymmetry among countries produces different incentives to manipulate price of capital. Capital-exporting countries try to raise its price to attract income from capital exports, whereas capitalimporting countries try to depress it to curtail import costs. These incentives are described by $\left(\bar{K}_{l}-K_{i}\right) \partial r / \partial \theta_{i}$ in Equation (24), which captures incentives to manipulate terms of trade. Since $d r / d \theta_{i}<0$, the sign of this term depends on the sign of $\bar{K}_{i}-K_{i}$, which represents the export-import balance. Without loss of generality, we assume $\bar{K}_{1}>\bar{K}_{2}$ and present Corollary 1 .

Corollary 1: When capital markets integrate, capital-importing Country 2 may redistribute more income redistribution, whereas capital-exporting Country 1 redistributes less.

Corollary 1 implies that capital market integration induces workers in capital-rich Country 1 to pursue skill-enhancing education. Conversely, it gives incentives to invest less in education if the terms of trade effect is sufficiently high in capital-poor Country 2. Capital-importing countries benefit from lower-cost capital and may adjust $\theta_{2}$ since its increase reduces the price of capital $\left(d r / d \theta_{2}<0\right)$. By contrast, capital exporters benefit 
from higher-priced capital and further reduce $\theta_{1}$ to increase its price. Overall, when incentives to manipulate the price of capital are dissimilar, the effects of capital market integration on capital-exporting countries do not change qualitatively. However, they may change for capital-importing countries.

\section{B. Emphasizing the welfare of unskilled labor}

In Section III, we assumed that the government considers the summed welfare of skilled and unskilled workers. We here assume that the social weight is applied to the utility of unskilled labor. Its objective is given by

$$
\begin{aligned}
W_{i}= & \int_{0}^{\tau_{i}^{*}} U_{s i} d \tau_{i}+\delta_{i} \int_{\tau_{i}^{*}}^{1} U_{L i} d \tau_{i} \\
= & Y_{i}\left(S_{i}, K_{i}, L_{i}\right)-\bar{T} K_{i}-\frac{\left(\tau_{i}^{*}\right)^{2}}{2}+\left(\delta_{i}-1\right)\left[\left(1-\tau_{i}^{*}\right) w_{L i}+\theta_{i} \tau_{i}^{*}\right] \\
& +\left[\tau_{i}^{*}+\delta_{i}\left(1-\tau_{i}^{*}\right)\right] u\left(g_{i}\right)+r\left\{\left[\tau_{i}+\delta_{i}\left(1-\tau_{i}^{*}\right)\right] \bar{K}_{i}-K_{i}\right\},
\end{aligned}
$$

where $\delta_{i}(\geq 1)$ denotes the importance of skill groups in the country's welfare function (Gerber and Hewitt 1987).

When capital markets are not integrated, the government chooses $\theta_{i}$ to satisfy ${ }^{5}$

$$
\theta_{i}^{\prime}=\frac{\left(1-\tau_{i}^{*}\right)\left(\delta_{i}-1\right)}{1+\left(\delta_{i}-1\right)\left(1-\tau_{i}^{*}\right)}\left\{\tau_{i}^{*}-\left[\bar{r} K_{i}+u\left(g_{i}\right)+b_{i}\right] \frac{\partial \tau_{i}^{*}}{\partial \theta_{i}}\right\}\left(-\frac{\partial \tau_{i}^{*}}{\partial \theta_{i}}\right)^{-1} \geq 0
$$

The final inequality comes from $0<\tau_{i}^{*}<1, \delta_{i} \geq 1$ and $d \tau_{i}^{*} / d \theta_{i}<0$. It is easily found that $\theta_{i}^{\prime}=0$ coincides with that in Section III if $\delta_{i}=1$.

When capital markets integrate, we have ${ }^{6}$

\footnotetext{
See Appendix 1.

${ }^{6}$ See Appendix 2.
} 


$$
\begin{aligned}
\theta_{i}^{*}= & \theta_{i}^{\prime}+\frac{\left(1-\tau_{i}^{*}\right)\left(\delta_{i}-1\right)}{1+\left(\delta_{i}-1\right)\left(1-\tau_{i}^{*}\right)}(\underbrace{\left.-\frac{\partial \tau_{i}^{*}}{\partial \theta_{i}}\right)^{-1}}_{+} \\
& \times[\underbrace{\left[\tau_{i}+\delta_{i}\left(1-\tau_{i}^{*}\right)\right] u_{g} \bar{T} \frac{\partial K_{i}}{\partial \theta_{i}}}_{-}+\underbrace{\left[\left[\tau_{i}+\delta_{i}\left(1-\tau_{i}^{*}\right)\right] \bar{K}_{i}-K_{i}\right]}_{?} \underbrace{\frac{\partial \tau}{\partial \theta_{i}}}_{=}] .
\end{aligned}
$$

In Equation (28), $\left[\tau_{i}^{*}+\delta_{i}\left(1-\tau_{i}^{*}\right)\right] u_{g} T d K_{i} / d \theta_{i}$ and $\left[\left[\tau_{i}+\delta_{i}\left(1-\tau_{i}^{*}\right)\right] \bar{K}_{i}-K_{i}\right] d r / d \theta_{i}$ are added to Equation (27). The former represents the positive effects of a lower $\theta_{i}$ on capital inflows; when the government redistributes less income, it induces workers to acquire skills, which boosts productivity of capital and attracts capital inflows. Eventually, the capital inflow increases the capital tax revenue, which benefits residents in country $i$ through the increase in the level of public goods provision. This effect appears in symmetric and asymmetric equilibrium and for all values of $\delta_{i} \geq 1$, which incentivizes governments to redistribute less income.

The latter of two effects added to Equation (27) has characteristics different from the former. It represents the effects of a decrease in $\theta_{i}$ on the price of capital. If the government reduces $\theta_{i}$, the number of skilled workers and the productivity of capital in production decline. Lower productivity moderates demand for capital, and its price in the integrated market falls. In general, the lower price of capital affects capital-exporting and capital-importing countries in opposing ways, and the impact of market integration on income redistribution is ambiguous. In symmetric equilibrium, however, that impact is clear.

Corollary 2: Assume symmetric equilibrium. The more the government emphasizes the welfare of unskilled workers, the greater its incentive to redistribute less income to them.

Proof. Inserting $\bar{K}_{i}=K_{i}$ into Equation (28), we have

$$
\begin{aligned}
\theta_{i}^{*}= & \theta_{i}^{\prime}+\frac{\left(1-\tau_{i}^{*}\right)}{1+\left(\delta_{i}-1\right)\left(1-\tau_{i}^{*}\right)} \underbrace{\left(-\frac{\partial \tau_{i}^{*}}{\partial \theta_{i}}\right)}_{+} \\
& \times[\underbrace{\left[\tau_{i}+\delta_{i}\left(1-\tau_{i}^{*}\right)\right] u_{g} \bar{T} \frac{\partial K_{i}}{\partial \theta_{i}}}_{-}+\underbrace{\left[\left(1-\tau_{i}^{*}\right)\left(\delta_{i}-1\right) \bar{K}_{i}\right]}_{+} \underbrace{\frac{\partial r}{\partial \theta_{i}}}_{-}],
\end{aligned}
$$


showing that $\left.\theta_{i}^{*}\right|_{\delta_{i}=1}>\left.\theta_{i}\right|_{\delta_{i}>1}$ (Q.E.D.).

This result is counterintuitive, but the intuition is straightforward. Governments that emphasize the welfare of unskilled workers $\left(\delta_{i}>1\right)$ have more incentive to increase their income. To do so, the government can increase capital income because the wage rate of unskilled labor is constant at $b$. Since policymakers believe $d r / d \theta_{i}<0$, they curtail the quantity of income redistributed in order to raise the price of capital and attract more.

\section{Conclusion}

This study has examined how capital market integration affects income redistribution and skilled-unskilled labor choices. Following earlier studies, we assumed that capital complements skilled labor and that unskilled workers show less complementarity with capital. We then examined how capital market integration alters income redistribution policies and the skilled-unskilled labor ratio. We also analyzed the efficiency of this ratio in equilibrium.

Our results revealed that competition for mobile capital following market integration compels governments to reduce income redistribution, thereby inducing workers to acquire skills. Because a greater supply of skilled labor raises net return on investment, the country attracts capital. Greater capital investment occasions capital outflows from other countries, reducing their tax revenues, provision of public goods, and welfare of their residents. This finding implies that policies to redistribute less income following market integration create negative externalities on other countries and induce governments to implement inefficiently low redistribution policies. In this case, the skilled-unskilled labor ratio becomes excessive.

These results offer two policy implications. First, in addition to the standard argument that the capital market integration improves the efficiency of capital allocation among countries, the market integration of capital should be advocated because it increases the individuals' incentives to be educated, and thereby enhances human capital accumulation. The long-term effect of market integration on educational incentives is noteworthy because accumulation of human capital boosts economic growth. The impact of market integration is not confined to workers' decisions to acquire skills and appears 
in long-run growth.

Second, market integration requires international coordination of policies to support low-income earners. This imperative condition arises because governments compete for mobile capital by excessively curtailing domestic income redistribution. In practice, governments seldom coordinate income redistribution policies; however, they do have alternatives, including harmonization of national education policies.

This study's focus differs from those of other studies in that the market integration influences not only on the choices of government policies but also on the choices of individual. The reactions of individuals are critical for the country in question to attract investment. For this reason, the governments are forced to reduce the domestic income redistribution with the capital market openings. These findings unable us, at least partly, to present the reason why we observe the increase in college-going rate with the progress of globalization.

Received 19 July 2016, Revised 20 January 2017, Accepted 25 January 2017

\section{References}

Agénor, P-Richard, "Benefits and costs of international financial integration: Theory and facts," The World Economy 26 (2003): 1089-1118.

Allen, Polly Reynolds and Jerome L. Stein, "Capital Market Integration,” Journal of Banking and Finance 14 (1990): 909-928.

Bucovetsky, Sam, "Asymmetric tax competition," Journal of Urban Economics 30 (1991): 167-181.

Cremer, Helmuth and Pierre Pestieau, "Factor mobility and redistribution," in Handbook of Regional and Urban Economics, ed. Henderson, J. Vernon and Jacques Thisse (Elsevier, 2004), 2529-2560,

Egger, Hartmut, Peter Egger, Josef Falkinger, and Volker Grossmann, "The impact of capital market integration on educational choice and the consequences for economic growth," The World Economy 33 (2010): 1241-1268. 
Galor, Oded and David N Weil, "The gender gap, fertility, and growth," American Economic Review 86 (1996): 374-387.

Gerber, Robert and Daniel P. Hewitt, "Tax competition and redistribution policy of local governments competing for business capital," Journal of Urban Economics 21 (1987): 69-82.

Gradstein, Mark and Moshe Justman, "Competitive investment in higher education: The need for policy coordination," Economics Letters 47 (1995): 393-400.

Hindriks, Jean, "The consequences of labour mobility for redistribution: tax vs. transfer competition," Journal of Public Economics 74 (1999): 215-234.

Hong, Qing and Michael Smart, "In praise of tax havens: international tax planning and foreign direct investment," European Economic Review 54 (2010): 82-95.

Kessler, Anke S., Christoph Lülfesmann, and Gorden Myers, "Redistribution, fiscal competition, and the politics of economic integration," Review of Economic Studies 69 (2002): 899-923.

Lee, Kangoh, "Does mobility undermine income redistribution? A political-support approach to redistribution in a Federation," FinanzArchiv 63 (2007): 186-210.

Peralta, Susana and Tanguy van Ypersele, "Factor endowments and welfare levels in an asymmetric tax competition game," Journal of Urban Economics 57 (2005): 258-274.

Viaene, J.-M. and Zilcha, I., "Public education under capital mobility," Journal of Economic Dynamics and Control 26 (2002a): 2005-2036.

Viaene, Jean-Marie and Itzhak Zilcha, "Capital markets integration, growth and income distribution," European Economic Review 46 (2002b): 301-327.

Wildasin, David E., "Income redistribution in a common labor market," American Economic Review 81 (1991): 757-774.

Wildasin, David E., "Factor mobility, risk and redistribution in the welfare state," Scandinavian Journal of Economics 97 (1995): 527-546.

Wilson, John D., "A theory of interregional tax competition," Journal of Urban Economics 19 (1986): 296-315.

Wilson, John D., "Tax competition with interregional differences in factor endowments," 
Regional Science and Urban Economics 21 (1991): 423-451.

Zodrow, George R. and Peter Mieszkowski, P., "Pigou, Tiebout, property taxation, and the underprovision of local public goods," Journal of Urban Economics 19 (1986): 356-370. 


\section{Appendix 1:}

The maximization gives

$$
\begin{gathered}
\frac{\partial W_{i}}{\partial \theta_{i}}=F_{S i} \frac{\partial S_{i}}{\partial \theta_{i}}+b_{i} \frac{\partial L_{i}}{\partial \theta_{i}}-\tau_{j}^{*} \frac{\partial \tau_{i}^{*}}{\partial \theta_{i}}+\left(1-\delta_{i}\right) r \bar{K}_{i} \frac{\partial \tau_{i}^{*}}{\partial \theta_{i}}+\left(1-\delta_{i}\right) u\left(g_{i}\right) \frac{\partial \tau_{i}^{*}}{\partial \theta_{i}} \\
+\left(\delta_{i}-1\right)\left[\tau_{j}^{*}+\left(\theta_{i}-b_{i}\right) \frac{\partial \tau_{i}^{*}}{\partial \theta_{i}}\right]=0 .
\end{gathered}
$$

Since Equation (7) and Equation (8) hold, we have

$$
\frac{\partial \tau_{i}^{*}}{\partial \theta_{i}}=\frac{\partial S_{i}}{\partial \theta_{i}}=-\frac{\partial L_{i}}{\partial \theta_{i}}
$$

Hence, using $R_{i}=\theta_{i} S_{i}$ and $\tau_{i}^{*}=w_{S i}-w_{L i}-\theta_{i}\left(1-\tau_{i}^{*}\right)^{-1}$, the first-order condition is rewritten as

$$
\begin{aligned}
\frac{\partial W_{i}}{\partial \theta_{i}}= & \left(F_{S i}-w_{S i}\right) \frac{\partial S_{i}}{\partial \theta_{i}}+\left(b_{i}-w_{L i}\right) \frac{\partial L_{i}}{\partial \theta_{i}}+\frac{\theta_{i}}{1-\tau_{i}^{*}} \frac{\partial \tau_{i}^{*}}{\partial \theta_{i}} \\
& +\left(1-\delta_{i}\right)\left[r \bar{K}_{i}+u\left(g_{i}\right)\right] \frac{\partial \tau_{i}^{*}}{\partial \theta_{i}}+\left(\delta_{i}-1\right)\left[\tau_{i}^{*}+\left(\theta_{i}-b_{i}\right) \frac{\partial \tau_{i}^{*}}{\partial \theta_{i}}\right] \\
= & \frac{\left[1+\left(\delta_{i}-1\right)\left(1-\tau_{i}^{*}\right)\right] \theta_{i}}{1-\tau_{i}^{*}} \frac{\partial \tau_{i}^{*}}{\partial \theta_{i}}-\left(\delta_{i}-1\right)\left[r \bar{K}_{i}+u\left(g_{i}\right)+b_{i}\right] \frac{\partial \tau_{i}^{*}}{\partial \theta_{i}}+\left(\delta_{i}-1\right) \tau_{i}^{*}=0 .
\end{aligned}
$$

Solving for $\theta_{i}$ yields Equation (27). 


\section{Appendix 2:}

Maximization gives

$$
\begin{aligned}
& \frac{\partial W_{i}}{\partial \theta_{i}}=F_{S i} \frac{\partial S_{i}}{\partial \theta_{i}}+\left(F_{K i}-T\right) \frac{\partial K_{i}}{\partial \theta_{i}}+b_{i} \frac{\partial L_{i}}{\partial \theta_{i}}-\tau_{i}^{*} \frac{\partial \tau_{i}^{*}}{\partial \theta_{i}}+\left(\delta_{i}-1\right)\left[\tau_{i}^{*}+\left(\theta_{i}-b_{i}\right) \frac{\partial \tau_{i}^{*}}{\partial \theta_{i}}\right] \\
&+\left\{\left[\tau_{i}^{*}+\delta_{i}\left(1-\tau_{i}^{*}\right)\right] \bar{K}_{i}-K_{i}\right\} \frac{\partial r}{\partial \theta_{i}}+r\left[\left(1-\delta_{i}\right) \bar{K}_{i} \frac{\partial \tau_{i}^{*}}{\partial \theta_{i}}-\frac{\partial K_{i}}{\partial \theta_{i}}\right] \\
&+\left(1-\delta_{i}\right) u\left(g_{i}\right) \frac{\partial \tau_{i}^{*}}{\partial \theta_{i}}+\left[\tau_{i}^{*}+\delta_{i}\left(1-\tau_{i}^{*}\right)\right] u_{g} T \frac{\partial K_{i}}{\partial \theta_{i}}=0 \\
& \Leftrightarrow \frac{\left[1+\left(\delta_{i}-1\right)\left(1-\tau_{i}^{*}\right)\right] \theta_{i}}{1-\tau_{i}^{*}} \frac{\partial \tau_{i}^{*}}{\partial \theta_{i}}-\left(\delta_{i}-1\right)\left[r \bar{K}_{i}+u\left(g_{i}\right)+b_{i}\right] \frac{\partial \tau_{i}^{*}}{\partial \theta_{i}}+\left(\delta_{i}-1\right) \tau_{i}^{*} \\
&+\left[\tau_{i}^{*}+\delta_{i}\left(1-\tau_{i}^{*}\right)\right] u_{g} T \frac{\partial K_{i}}{\partial \theta_{i}}+\left\{\left[\tau_{i}^{*}+\delta_{i}\left(1-\tau_{i}^{*}\right)\right] \bar{K}_{i}-K_{i}\right\} \frac{\partial r}{\partial \theta_{i}}=0 .
\end{aligned}
$$

Solving for $\theta_{i}$, we get Equation (28). 